\title{
垂直二層膜媒体ノイズの記録磁界依存性
}

\section{Dependence of Medium Noise on Writing Field in Double-layer Perpendicular Media}

\author{
三浦 健司 - 村岡 裕明 - 中村 慶久 \\ 東北大学疍気通信研究所, 仙台市青葉区片平 2-1-1
}

K. Miura, H. Muraoka, and Y. Nakamura

RIEC, Tohoku Univ., 2-1-1, Katahira, Aoba-ku, Sendai 980-8577

(2000年 10 月 6 日受理、2001年1月 24 日採録)

We investigated the dependence of media noise on the writing head in perpendicular magnetic recording. Transition noise modeling, discussed first, provided measurements for various write heads to determine head field influence. Results show that transition jitter corresponding to medium noise correlates with the head field gradient. Sharpening head field gradient is thus an efficient method for reducing the medium noise.

Key words: medium noise, single-pole head, perpendicular double-layer medium, transition jitter, head field gradient

\section{1.はじめに}

垂直磁気記録における重要な課題の一つがメディアノイズの低减 である。垂直媒体のノイズ起源しして転移間の減磁界により生じる微 細磁化反転が示されている。 ${ }^{1}$ しかし、軟磁性裹打ち層を持つ二層膜 型の垂直媒体では、スペクトラム積分による実効值ノイズ電圧が線記 録密度の平方根に比例して増加する傾向が䚁測されており、転移性 ノイズの存在が示唆されていた。筆者らは垂㨁二層膜媒体に単磁極 ヘッドにより記録を行なった場合について、時間朝解析によってイ ズの発生源が転移付近にあることを示し、転移性ノイズが主であること を明確にした 2)。これはメディアノイズ電圧と転移位貫変動(転移ジッ タ）が対応することを意味しており、メディアノイズの低減はジッタの低 减亡等価である。

垂直一層膜媒体のメディアノイズの議論はこれまで数多くなされて きた。本来、メディアイイズは記録媒体の微細構造に深く関わるため、 記録媒体の微細構造制御、例えば、媒体記録層の粒子サイズと粒子 間の磁気的な結合、配向性、角型比、などが重視されてきた。特に、 記録再生特性や MFM などで観測される等洒的な磁気単位(クラス タ）は粒子サイズより大きい場合が多いため、クラスタサイズの低减の ために粒子間の磁気的孤立化の促進に大きな努力が払われてきた。 一方で、磁化転移の性状を含めた記録磁化分布を決定する記録過 程とメディアノイズ、特に記録へッド磁界とメディアノイズの関係は必 ずしも十分な議論がされていなからた。

本論文では、垂直磁気記録の記録過程における転移の形成を考 察し、実験を通して明らかにすることを試みた。すなわち、種々の記 録へッドに対して記録電流の変化に対するメディアノイズを測定し、 記録磁化が決定される媒体保磁力付近の記録へッド磁界勾配に着目 してジッ夕量との定性的な関係について考察した。その概要を以下
に報告する。

\section{2. 記録ヘッド磁界勾配と転移ジッタ年との関係}

箨者らは時間軸解析により得られる転移ジッ夕量が磁化転移付近 に集中し、ランダム多角形(Voronoi œll)モデルとの定量的な比較から ジッ夕量は磁気的クラスタ径に対応する結果を得ている。よって、 低ノイズ化のためにはこのクラスタ径の微細化が直接的なアプロー チとなり、記録媒体の微細磁気構造の検討が必要である。しかし、こ のノイズは磁化転移に関わるものであり、記録転移形状は媒体の磁 気的構造だけでなく記録過程でも決定される。平均磁化転移幅だけ ではなく、このクラスタ形成も記録過程における要因が影響する可能 性がある。換言すれば、ノイズ低減には記録媒体の改良だけではな く記録プロセスパラメータを改善することで効果が期待できる可能性 がある。

図 1 は磁化転移ジッ夕量とヘッド磁界勾配との関係を、記録媒体の 保磁力分散 Switching field distribution (S.F.D.) と関連させて、概念的 に示したものである。ここで、同図は磁化転移が形成されるへッド磁 界が反転した瞬間の磁界勾配が楥急の 2 通りで、右側の保磁力分散 に対応して上側に示す磁化転移の広がりが異なる様子を表している。 いったん主磁極中央付近で飽和に達した後、反磁界を含めた実効 壮磁界が記録層保磁力に等しくなる点で磁化転移が形成される。こ の際に、ヘッド磁界勾配が緩やかであれば、保磁力分散を有する 個々の媒体微粒子がダウントラック方向に広い分布を持って反転領 域を形成する。すなわち、平均転移位置力ら離れていても磁界公配 が楥やかなために反転する(あるいは反転し切れない)粒子が残存し

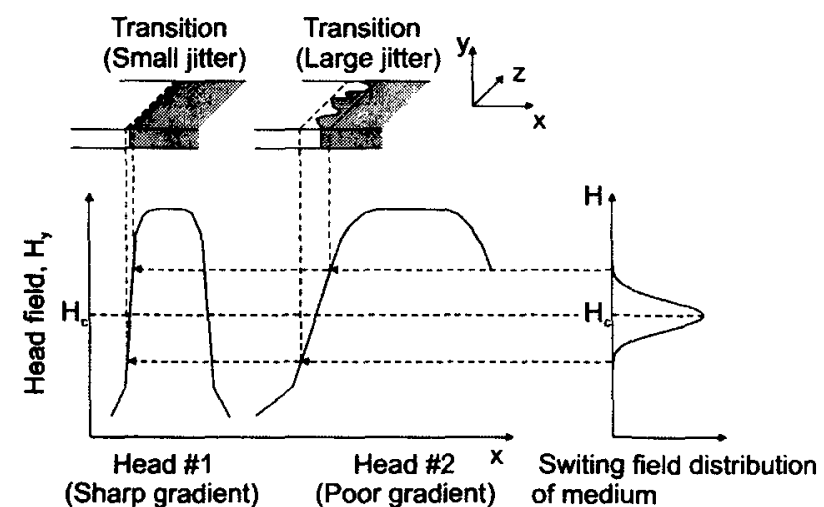

Fig. 1 Relation between head field gradient and transition jitter. 
Table 1 Heads and medium specification.

\begin{tabular}{|c|c|}
\hline \multicolumn{2}{|l|}{ Write heads } \\
\hline - FeSiN SPT head $\left(B_{\mathrm{s}}: 1.9 \mathrm{~T}\right)$ & \\
\hline Track width & $5 \mu \mathrm{m}$ \\
\hline Main-pole thickness & $400 \mathrm{~nm}$ \\
\hline $\begin{array}{l}\text { Number of coil turns } \\
\left.\text { - CoZrNb SPT head ( } B_{s}: 1.2 \pi\right)\end{array}$ & 3 turns \\
\hline Track width & $5 \mu \mathrm{m}$ \\
\hline Main-pole thickness & $400 \mathrm{~nm}$ \\
\hline Number of coil turns & 2 turns \\
\hline - Thin film ring head & \\
\hline Write gap length & $0.27 \mu \mathrm{m}$ \\
\hline Number of coil turns & 11 turns \\
\hline \multicolumn{2}{|l|}{ Read head: GMR head } \\
\hline $\begin{array}{l}\text { Track width } \\
\text { Shield gap length }\end{array}$ & $\begin{array}{r}0.9 \mu \mathrm{m} \\
0.15 \mu \mathrm{m}\end{array}$ \\
\hline \multicolumn{2}{|c|}{ Medium: Perpendicular double-layered medium } \\
\hline $\begin{array}{l}\text { CoCrTa Recording layer } \\
\left(M_{\mathrm{s}}: 400 \mathrm{emu} / \mathrm{cc}, H_{\mathrm{c} \perp}: 2800 \mathrm{Oe},\right. \\
\left.\qquad M_{\mathrm{r}} / M_{\mathrm{s}}: 0.69\right)\end{array}$ & $50 \mathrm{~nm}$ \\
\hline Ti Seed layer & $5 \mathrm{~nm}$ \\
\hline CoZrNb Underlayer ( $\left.\mathrm{B}_{\mathrm{s}}: 1.2 \mathrm{~T}\right)$ & $600 \mathrm{~nm}$ \\
\hline
\end{tabular}

て転移領域が広がり、従って、個々の転移位置の理想位置からの分 散であるジッ夕量が大きくなる。

このことはわずかな交換相互作用によって記録層磁性結晶粒が数 個集まり同一磁気的挙動を示すクラスタを形成する機会が増えること も意味する。すなわち、磁気クラスタ径が大きくなる。逆に急峻なへ 壮磁界勾配であれば磁気的クラスタが小さく形成され、磁化反転の 開始位置と終了位㯰との間隔が狭くなることが予想される。磁気的〉 ラスタサイズは記録過程、特に記録層保磁力付近のヘッド磁界勾配 に依存する可能性がある。この場合に転移付近で実効へッド磁界が 直楾的であれば、転移ジッタ量はへッド磁界勾配の逆数に比例して 改善されることが期待される。

\section{3. 实験方法}

本測定では複数の記録へッドと、それぞれのヘッドにおいて記録 電流を変化させることにより、記録へッド磁界分布、すなわちへッド磁 界公配ならびにヘッド磁界強度の変化を与えた。測定に用いたへ ッド・ディスクの諸元を表1に示す。記録へッドには主磁梪膜厚、トラッ ク幅の主磁極形状が等しく、主磁極飽和磁束密度 $\left(B_{\mathrm{s}}\right)$ が FeSiN $の$ 1.9 T、 $\operatorname{CoZrNb}$ の $1.2 \mathrm{~T}$ と異なる2 種類の単磁極へッド 1)と、薄膜リン グヘッドを用いている。記録媒体には CoZrNb アモルファス裏打ち 層の上に Ti シ一ド層を有する垂直二層膜媒体を用い、ディスクの回 転速度を $7.62 \mathrm{~m} / \mathrm{s}$ に設定した。このときのヘッド浮上量はおよそ 30 nmである。

転移ジッ夕量ならびにハードトランジションシフト (HTS) 測定は、 $10 \mathrm{kfci}$ の定周期信号を記録した際の再生波形を重曽する時間軸解

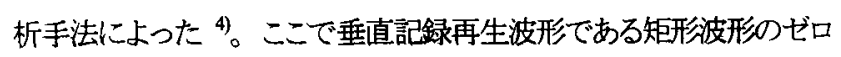
クロス点の摇らぎ距離の標準偏差をジッタ量 $\sigma_{\text {触 }}(\mathrm{nm})$ とし、転移間
距離に相当する矩形波形の立ち上がりから立ち下がりの距離と立ち 下がりから立ち上がりの距離の差より HTS (nm)を算出した。

\section{4. ジタ量 測定結果}

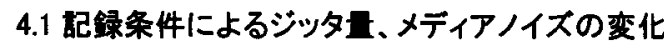

3 種類の記録へッドによる再生出力とジッタ距離の記録起磁力依存 性を図 2 に示す。再生出力が最大值を示す最適起磁力においてジ ッタ量が最小值となる。特に現状の単磁極へッドと CoCr 系二層膜媒 体の場合、記録起磁力の増加とともにヘッド磁界勾配とへッド磁界強 度が同時に増大することが予想される。本測定でも、最大起磁力もし くはその近傍で再生出力が最大でジッタ量が最小となる測定結果を 得た。一方、薄膜りングヘッド記録では上部磁極の断面樌が大きい ことにより過大な起磁力では裹打ち層が磁気飽和を起こし、へッド磁 界勾配が少化して記録㨔磁を生じる恐机がある。本測定において、 最大再生出力を与える最適起磁力を越えた場合にははつきりした記 録減磁が認められたが、これに対応してジッ夕量も増减する傾向が 明らかである。

ここで用いたへッド構造と単磁極へッド主磁極の飽和磁束密度 $B_{\mathrm{s}}$ の值を考えると、薄膜リングヘッドはその垂直記録磁界成分を用いる ことから単磁極へッドに比べると記録磁界勾配が緩慢である。また、 単磁極へッドについては、ヘッド磁界分布が同一であって最大記録 磁界強度は主磁極の飽和磁束密度に応じて大きくなるために、絶対 值で考える磁界勾配は主磁極の飽和磁束密度が高いほど大きくなる と考えられる。すなわち、薄膜Uングヘッド、CoZrNb 単磁極へッド、 FeSiN 単磁極へッドの順にヘッド磁界勾配がより急峻になることが予 想される。図2より、それぞれの記録へッドにおいて達成できる最小 ジッ夕量は上記の順に $11.0 \mathrm{~nm}, 9.1 \mathrm{~nm}, 7.7 \mathrm{~nm}$ と小さくなる結果が得ら れている。

なお、記録へッド磁界公配は磁化転移形状にも大きく影響すること がわかっているが、本実験において記録分解能の点から考察すると、 低密度記録出力の半分の出力を呈する記録密度 $\left(D_{50}\right)$ の值は、 3 種 類のヘッドを用いたときの最適起磁力で、それぞれ $115 \mathrm{kfci}, 130$

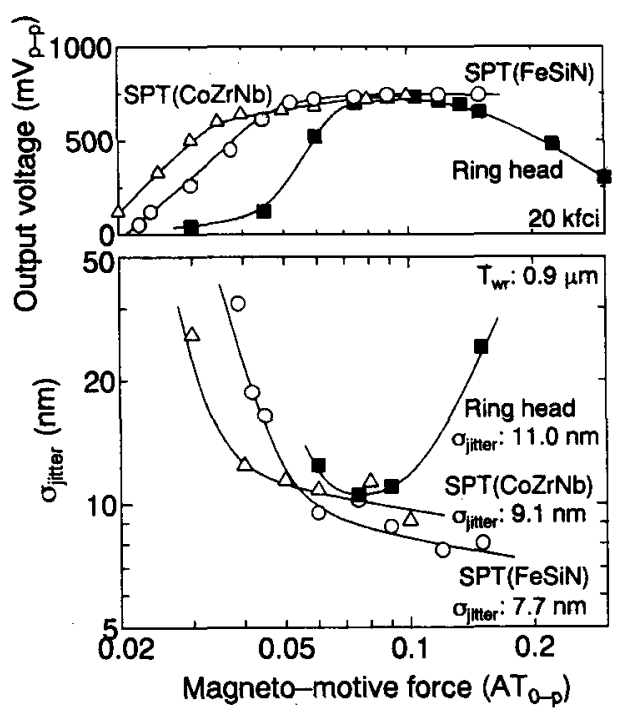

Fig. 2 Dependence of output voltage and jitter on MMF among three writing heads. 


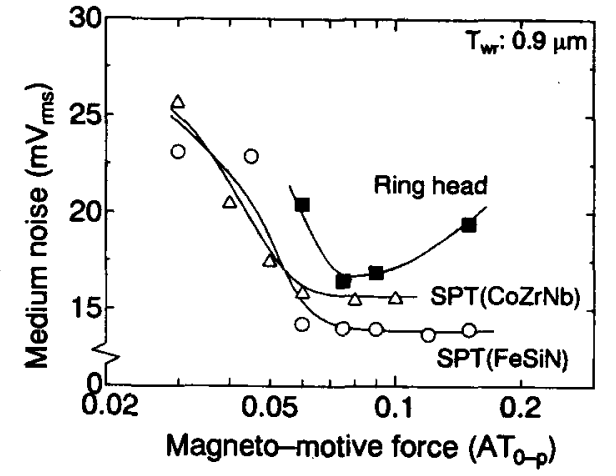

Fig. 3 Dependence of RMS noise voltage on MMF among three writing heads.

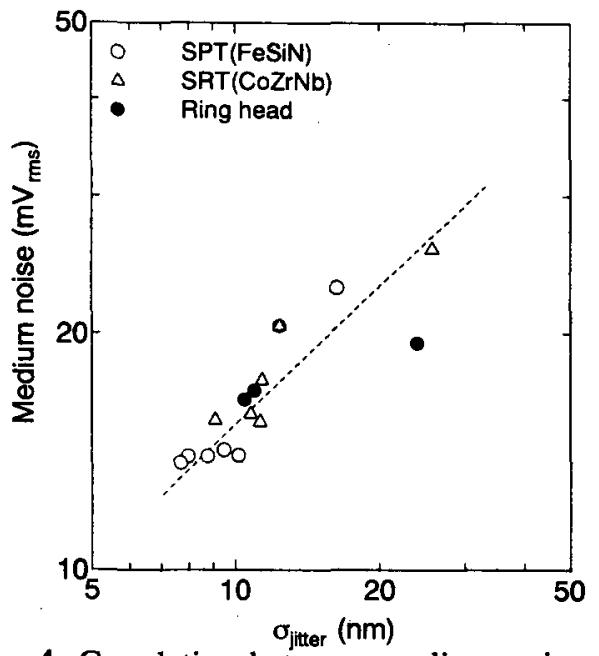

Fig. 4 Correlation between medium noise and transition jitter.

kfci, 150 kfci となった。確力に、へッド磁界勾配の急峻性はメディア， イズ低减だけでなく、記録高分解能化にも奇与していることが確認で きる。

図 3 には各記録へッドにおけるメディアノイズ電圧を記録起磁力に 対して示したものである。ジッ夕距離が十分小さなところでメディア， イズ電死も抑えられている。従って、メディアイイズ自体も上記のジッ 夕量に類似の傾向を持つ。これをより明らかに示すために、各記録 ヘッド、各起磁力におけるジッタ量とメディアノイズ電圧の相関を図 4 に示す。ジッタ量とメディアノイズ電圧值には明確な正の相関が存 在し、シッ夕低减がメディアノイズ抑制に効果的であるとともに、メディ アノイズの議論をジッ夕量に帰着させて良いことが示されている。

\section{2 ハードトランジションシフトの纪録起磁力依存性}

ヘッド磁界勾配に依存するもう一つのパラメータが HTS である。 HIS は、前歴磁化からの磁界がヘッド磁界に重曽されることで実効 的な記䩮へッド磁界が増減して転移位置がシフトする現象であり、高 密度ほどビッ卜長に対するシフト量が相対的に大きくなり影響が強い ことが知られている。ここで、へット磁界勾配が急聺であれば前歴か らの干濒磁界の大きさが同一であっても、媒体の反転磁界に等しくな る磁界強度を与える位置の変動が小さいので、HTS も小さくなる。 のことは同一媒体に対するHTSの大きさが記䟿へッドによって変化し

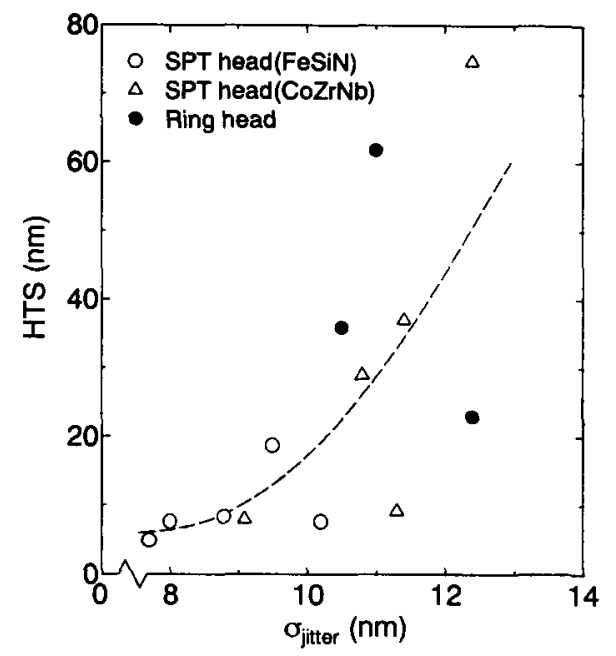

Fig. 5 Dependence of HTS on the amount of transition jitter among three writing heads.

た場合には、その磁界勾配強人関車すると考えられる。図 5 は、本 測定系においてこれを測定したもので、HTS どシッ夕量の相関を示し ている。

必ずしも強い相関ではないものの、ジッ夕量が大きくなる場合はそ れに対応して HTS も增大していることが分かる。これは上記の議論 に従えば、へッド磁界勾配の緩慢化によってジッタ量が大きくなること を示している。すなわち、ジッ夕量とヘッド磁界勾配との関係には相 関があることが確認できた。

\section{5. ジッタ贯とヘッド磁界勾配との関保}

ところで、各記録へッドの各記録起磁力におけるへッド磁界勾配の 具体的な值はコンピュータシミュレーションによる数值計算で推定す ることが可能である。ここでは、記録層の非線形磁化特性を考虑した 二次元有限要素法を用いるシミュレーションで求めた。ただし、計 算は静的なへッド磁界強度を求めるもので、実際の記録に対応する 磁化転移を記録する状態のシミュレーションは行なっていない。単 磁極へッドにおいては主磁極先端部分が開磁路構造を有しているの で、磁路中に挿入される記録媒体磁気特性のモデリングは重要であ る。本計算では媒体の非線形磁化特性を考虑したへッド磁界分布を 求め、記録層中央部分での磁界強度をもってヘッド磁界とした。

ただし、ある記録起磁力に対して計算で得られたへッド磁界分布 がそのまま対応する記録電流でのへッド磁界である保証はないので、 何らかの校正を行なう必要がある。ここでは、リバースDCイレーズノ イズ測定法を用いて実際の記録起磁力との対応させた。すなわち、 記録へッド磁界が媒体の平均反転磁界に等しい際に観測される媒体 ノイズが最大になる垂直媒体の性質を用いて、媒体ノイズの記録電流 依存性を観測して最大ハイズ電圧を与える電流値において、ヘッド磁 界強度が媒体の反転磁界(近似的に保磁力に等しい。)として計算結 果の校正を行なった。

記録へッドに FeSiN 単磁極へッドを用いたときのリバース DC イ ーズノイズ特性の測定結果を図 6 に示すが、同図で媒体ノイズがピ 


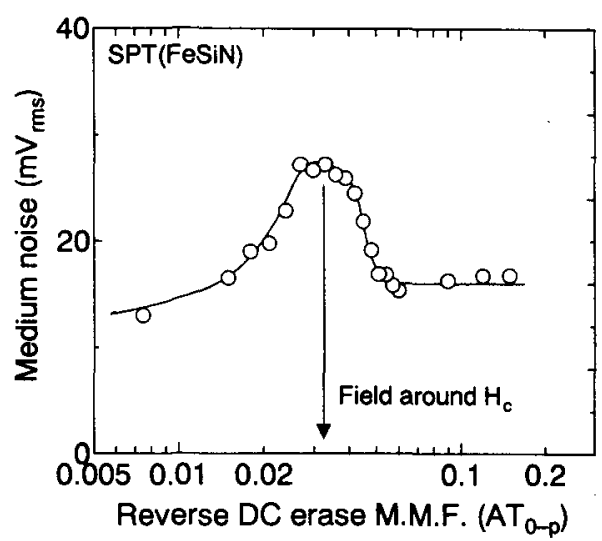

Fig. 6 Reverse DC erase noise characteristics for FeSiN SPT head.

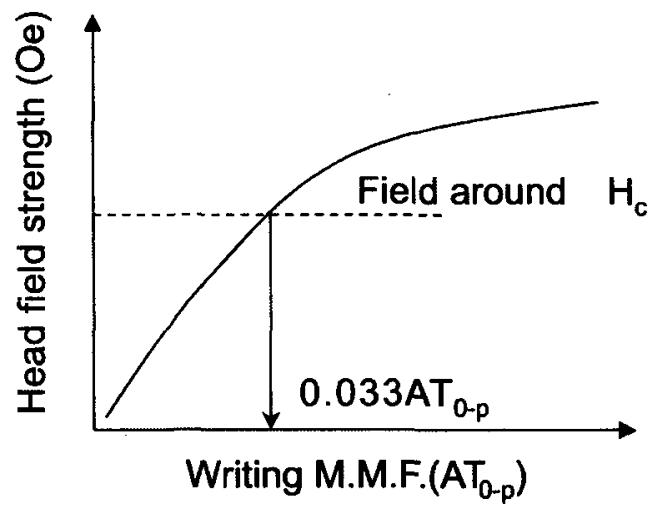

Fig. 7 The diagram of the M.M.F. calibration on simulation using Reverse DC erase noise characteristics.

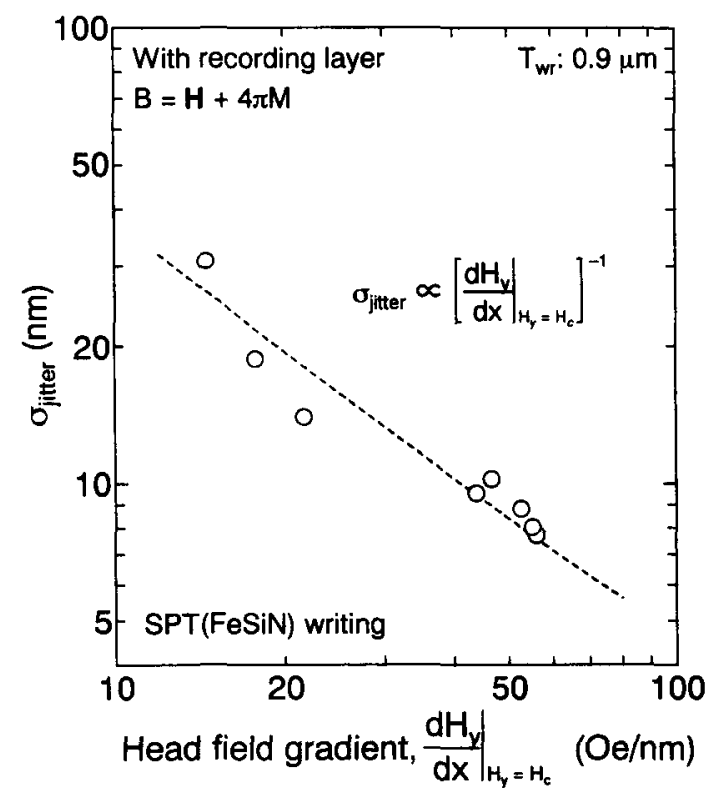

Fig. 8 Relation between transition jitter and head field gradient around $\mathrm{H}_{\mathrm{c}}$.

一クを呈する記録起磁力(0.033 AT)で、へッ磁界強度と記録層保磁 力(3200 Oe)が等しくなったとした。図7にはシミュレーション起磁力
に対するへッド磁界強度の概念図を示す。計算で得られる最大へッ ド磁界强度の起磁力依存性に対して、上記のようにしてシミュレーシ ヨンとリバースDCイーズ測定から求めた点でフィッテイングを行なう ことで、測定各起磁力でのヘッド磁界分布ならでに勾配の算出を行 った。図8は、FeSiN単磁極へッドでの記録磁界公配に対して、転移 ジッタ量をプロットしたものである。同図より、記録磁界公配が増加す るにつれてジッタ距離が堿少しており、記録条件がジッ夕量に対して 大きな影锌を与えることが明らかである。なお、同図中の破袙はジッ 夕量がヘッド磁界勾配の逆数に比例する場合に対応するもので、測 定値と妥当な一致を示しており、冒頭で述べたへット磁界勾配に対し てジッタ量はほぼ反比例して変化していると言える。

$$
\text { 6. まとめ }
$$

垂直二層膜媒体で支配的な転移性ノイズの抑制について検討し た。その結果、転移位置のジッ夕量と一ット磁界勾配には密接な関係 のあることが明らかになった。薄膜りングヘッドと飽和磁束密度の異 なる主磁極を持つ単磁極へッドについて、記録起磁力を変化するこ とによるジッタ量を測定するとともに、まず、ハードトランジションシフト から判断したへッド磁界勾配が急峻になる起磁力でジッ星が小さい 值になることを実験的に示した。さらに、リバース DC イレーズ測定 によりキャリブレーションを行なった計算機シミュレーションを用いて ヘッド磁界勾配を算出してジッタ量との相関を調べ、よく対応すること を示した。以上より、メディアノイズを低堿するには、媒体の微細磁 気構造を改善することの他に、急崚な記録一ッ卜磁界勾配主必要であ ることを明らかにした。

謝 辞 ここで用いた FeSiN 単磁喠ヘッドは秋田高度技術研究所 山川、伊勢両氏にご提供いただいた。謝意を表する。本研究には、 文部省科研費、NEDO、SRC、日本学術振興会未来開拓学術研究 推進事業の援助を得ている。

\section{女 献}

1) N. Honda, T. Kiya, and K. Ouchi; J. Mag. Soc. Jpn, 21(Suppl. No. S2), 505 (1997).

2) 三浦健司、村岡裕明、杉田恒、中村慶久; 日本応用磁気学会誌, 24, 231-234 (2000).

3) 駒込博泰、島津武仁、吉田亮一、渡辺功、村岡裕明、杉田愃、中 村慶入; 日本応用磁気学会誌, 24, 243-246 (2000).

4) T. Korenari, T. Matsutera, S. Tsuboi, K. Tagami,J. Mag. Soc. Jpn, 17, S2(1993).

5) Y. Nakamura, I. Tagawa, IEEE Trans. Magn., MAG-25, No.5(1988).

6) H. Aoi, M. Saitoh, N. Nishiyama, R. Tsutiya, T. Tamura, IEEE Trans. Magn., 26, No.5(1990). 